\title{
Hospital resources and myocardial infarction case fatality: the IBERICA study
}

\author{
Recursos hospitalarios y letalidad por infarto de miocardio. Estudio IBERICA
}

Eva E. Álvarez-León, Roberto Elosua, Alberto Zamora, Elena Aldasoro, José Galcerá, Hermelinda Vanaclocha, Antonio Segura, Miquel Fiol, Javier Turumbay, Gloria Pérez, José M. Arteagoitia, María J. Tormo, Adolfo Cabadés, Gema Vega, José I. Ayestarán, Vega García, Iraida Hurtado-de-Saracho, Carmen Navarro, Óscar Zurriaga, Javier Muñiz, Joan Salam, Dr Jaume Marrugata, the investigators of the IBERICA Study

\begin{abstract}
Introduction and objectives. To determine the proportion of patients with myocardial infarction (MI) not admitted to a coronary care unit (CCU), the variables associated with admission into a $\mathrm{CCU}$, and whether admission to a CCU, and the availability of coronary angiography in the same hospital, were associated with 28-day case fatality.

Patients and method. Population-based registry of MI in patients 25 to 74 years of age, admitted during 1996-1998. Demographic and clinical characteristics were recorded, as well as management, clinical course and survival after 28 days. Hospitals were classified according to the availability of a CCU and catheterization laboratory (advanced hospital), CCU only (intermediate hospital) or neither (basic hospital). Admission to the CCU was also recorded. Results. In all, 9046 cases of MI were recorded; in $11.3 \%$ the patient was not admitted to a CCU. Age, smoking $(\mathrm{OR}=1.33$; 95\% CI, 1.08-1.64), non-Q MI (OR=0.62; 95\% CI, 0.49-0.78) or undetermined location of MI $(\mathrm{OR}=0.34$; 95\% CI, 0.23-0.50), Killip 4 score on admission (OR=0.63; 95\% CI, 0.40-1.00) and delay in arrival at the hospital $>6$ $\mathrm{h}$ were associated with CCU admission. Patients admitted to a CCU showed a lower case fatality in the first $24 \mathrm{~h}$ $(4.2 \%$ vs $23.5 \%)$, which was independent of comorbidity, severity and treatment. The 24 -hour survivors admitted to a basic hospital had higher case fatality $(17.3 \%$ vs $7.8 \%)$ than other groups, which was related to differences in treatment.

Conclusions. CCU admission is associated with a lower case fatality in the first $24 \mathrm{~h}$. Admission to a basic hospital is associated with a higher 28-day case fatality even in patients who survive $24 \mathrm{~h}$.
\end{abstract}

\footnotetext{
Resumen

Introducción y objetivos. Determinar el porcentaje de pacientes con infarto agudo de miocardio (IAM) que no ingresan en una unidad de cuidados intensivos coronaries (UCIC), las variables asociadas al ingreso en una UCIC y si el ingreso en una UCIC, su disponibilidad y la de hemodinámica en el hospital se asocian a la letalidad a 28 días. Pacientes y método. Registro poblacional (1996-1998) de casos de IAM en pacientes con edades comprendidas entre los 25 y los 74 años. Se recogieron variables demográficas, clínicas, el ingreso en UCIC y la letalidad a los 28 días. Se clasificaron los hospitales según la disponibilidad de UCIC y hemodinámica (hospital avanzado), solamente UCIC (hospital intermedio) o ninguno (hospital básico).

Resultados. Se registraron 9.046 casos; el 11,3\% no ingresó en una UCIC. La edad, el consumo de tabaco (odds ratio $[\mathrm{OR}]=1,33$; intervalo de confianza $[\mathrm{IC}]$ del 95\%, 1,08-1,64), el infarto sin onda Q (OR = 0,62; IC del 95\%, 0,49$0,78)$ o ilocalizable $(\mathrm{OR}=0,34$; IC del 95\%, 0,23-0,50), el grado Killip 4 al ingreso (OR = 0,63; IC del 95\%, 0,40$1,00)$ y el retraso $>6 \mathrm{~h}$ en llegar al hospital se asociaron al ingreso en UCIC. Los pacientes ingresados en UCIC presentaban menor letalidad que los ingresados en hospitales básicos en las primeras 24 h (el 4,2 frente al 23,5\%), independientemente de la gravedad del IAM y de las variables relacionadas con el tratamiento. Los su-pervivientes a $24 \mathrm{~h}$ que ingresaban en un hospital bÁsico presentaban mayor letalidad a los 28 días (el 17,3 frente al 7,8\%), relacionada con las variables de tratamiento.

Conclusiones. El ingreso en una UCIC se asocia a una menor letalidad de los pacientes con IAM en las primeras $24 \mathrm{~h}$. El ingreso en un hospital bÁsico se asocia a una mayor letalidad a los 28 días.
} 
Key words

Epidemiology; Myocardial infarction; Mortality; Fatality

Palabras clave

Epidemiología; Infarto de miocardio; Mortalidad; Letalidad

\section{ABBREVIATIONS}

IBERICA:, Investigación, Búsqueda Específica y Registro de Isquemia Coronaria Aguda [Research, Specific Search and Registry of Acute Coronary Ischemia]; AMI:, acute myocardial infarction; CCU:, coronary care unit; PRIAMHO:, Proyecto de Registro de Infarto Agudo de Miocardio Hospitalario [Project for a Hospital Registry of Acute Myocardial Infarction]; MONICA:, Monitoring the Trends and Determinants of Cardiovascular Disease

\section{Introduction}

More than 74000 patients are hospitalized every year in Spain for acute myocardial infarction (AMI) or unstable angina. ${ }^{1}$ The recommendations contained in the basic guidelines indicate that patients with AMI should be treated in a coronary care unit (CCU) or other hospital area with the capability for continuous electrocardiographic monitoring and defibrillation for at least the first 48 hours of the acute phase. $^{2-4}$

Furthermore, the relationship between coronary angiography usage in patients with AMI and mortality continues to be a subject for debate. ${ }^{5-9}$ On-site availability of the technique leads to greater usage, ${ }^{5,8,10}$ although its implementation is not always associated with lower mortality ${ }^{5,7,8}$ but is probably associated with better quality of life. ${ }^{11}$

The Spanish Ley General de Sanidad [General Health Act] of $1986^{12}$ and the Spanish Ley de Cohesión y Calidad del Sistema Nacional de Salud [National Health System Cohesion and Quality Act] of $2003^{13}$ establish the principle of equal and universal coverage in the public healthcare system, ensuring access to healthcare benefits under conditions of effective equality.

Several studies have analyzed variability in the management of patients with AMI in Spanish CCUs and the relationship between this variability and prognosis, ${ }^{7,14,15}$ but few have included patients who were not admitted to a CCU. ${ }^{5,6,16}$

The purpose of this study was to determine the percentage of AMI patients who were not admitted to a CCU and the variables associated with CCU admission, as well as to evaluate whether the availability of a CCU or catheterization laboratory at the hospital where the patient spent most of the first 72 hours from the onset of symptoms was associated with 28-day case-fatality.

\section{Patients and methods}

Design

The IBERICA study (Investigación, Búsqueda Específica y Registro de Isquemia Coronaria Aguda; Research, Specific Search and Registry of Acute Coronary Ischemia) is a population-based registry of patients with AMI among 25- to 74-year-old residents in various areas of the Balearic Islands, Basque Country, Castilla-La Mancha, Catalonia, Murcia, Navarra, and Valencia. The study period was 1 July 1996 to 31 December 1998 in most of the areas. According to official projections, the referral population in the areas for the study period was 3638940 men and 3725742 women.

\section{Patients}

All patients with AMI admitted to a CCU in the participating areas were prospectively recorded. In addition, all medical histories were reviewed for all patients with codes 410-414 of the International Classification of Diseases, Ninth Revision, listed as a diagnosis at discharge from hospitals in the participating areas. The emergency department records and the emergency health transport records were also reviewed to identify cases transferred to referral hospitals outside the study area. In patients who presented several episodes of AMI, each event was recorded as a separate case.

The standardized criteria of the MONICA study ${ }^{17}$ were used for the AMI diagnosis. The analysis included patients arriving at a hospital alive and classified as definite AMI, whether alive or dead, as well as possible cases in which the patient died after arrival to the hospital. In summary, the cases were classified as: a) definite AMI, when a Q-wave appeared in the electrocardiogram or when 
electrocardiographic abnormalities were observed suggesting ischemia with typical symptoms and myocardial enzyme levels (creatine kinase $[\mathrm{CK}]$ ) greater than twice the upper limit of normality, and when there was a fatal event with signs of coronary thrombosis or recent myocardial necrosis on autopsy, and b) possible infarction, when patients did not have the criteria of definite infarction and died having presented typical symptoms, or when they presented signs of coronary arteriosclerosis or ischemic heart disease on autopsy.

\section{Follow-up and Events of Interest}

The main event of interest during follow-up was 28-day case-fatality. All deaths occurring during the first 28 days post-AMI and considered to be related to the index event were recorded. Patients' vital status at 28 days was ascertained by a review of the medical history, contact with the attending physician or the death registry. A distinction was made between 24-h mortality and mortality occurring between $24 \mathrm{~h}$ and 28 days from the onset of symptoms.

\section{Variables Measured}

The factor of interest analyzed was the type of hospital where the patient stayed for most of the first $72 \mathrm{~h}$ from the onset of symptoms. The hospitals were classified as one of the following: a) basic hospital if there was no CCU or catheterization laboratory; b) intermediate hospital if there was a CCU but no catheterization laboratory, and c) advanced hospital if both a CCU and a catheterization laboratory were available. In addition, the patients from the intermediate and advanced hospitals were classified according to whether or not they had been admitted to a CCU. In accordance with the definition of the PRIAMHO (Proyecto de Registro de Infarto Agudo de Miocardio Hospitalario, Project of a Hospital Registry for Acute Myocardial Infarction) study, ${ }^{14,15}$ this analysis looked at all patients admitted to a CCU or general intensive care unit (ICU) that handled coronary patients.

Data were also compiled with regard to demographic information, clinical characteristics, comorbidity (hypertension, diabetes, and heart failure), smoking, complications (maximum Killip class, severe ventricular arrhythmia), as well as the delay between the onset of symptoms and arrival at the hospital and the diagnostic and therapeutic procedures carried out during the hospital stay.

\section{Quality Control}

In order to ensure the homogeneity of the methods and the data compiled, the investigators were trained and accredited for the study by the coordinating center. Intraobserver and interobserver agreement when categorizing a set of index cases was analyzed, obtaining Kappa indices of agreement $>0.90$ for all investigators. In addition, the coordinating center blindly assigned a diagnostic category to each case by means of an automatic algorithm. If there was any disagreement between the coordinating center and the principal investigator, the case was reviewed and a diagnostic category was agreed.

\section{Statistical Analysis}

Continuous variables are presented as the mean and standard deviation, and were compared between groups by a Student's $t$ test or analysis of variance. Categorical variables are shown as percentages and were compared between groups by a chi-square test. For the trend analysis between hospital types, the chisquare test for trends was used in the case of categorical variables, and the Spearman correlation for ordinal variables.

Logistic regression was used to identify the variables associated with CCU admission and to estimate the odds ratio (OR) and 95\% confidence interval (CI) for mortality of admitted patients at 28 days, within the first 24 hours and from 24 hours to 28 days, according to hospital type and CCU admission, adjusted for the main confounding factors. Variables that differed by a significance level of $P<.15$ in the bivariate analysis between hospital types and that were also associated with the dependent variable (28-day casefatality) were considered potential confounding factors. Clinically relevant variables were also considered. When analyzing the association between hospital type and case-fatality, four different models were defined. Models 1 and 2 were adjusted for age and sex, and for comorbidity, respectively. In order to assess whether the differences observed were related to AMI severity and management, the model included Killip class and the presence of malignant ventricular arrhythmia in addition to comorbidity 
(Model 3) and treatment with thrombolysis and aspirin therapy (Model 4). SPSS 10.0 was used for the calculations.

\section{Results}

During the study period, 9304 patients with AMI were recorded at the hospitals in the participating areas. Among these, the treatment hospital type in the first 72 hours or CCU admission was unknown in 258 patients $(2.8 \%)$. Among the 9046 patients with AMI included in the analysis, $202(2.2 \%)$ were admitted to a basic hospital, 359 (4.0\%) to an intermediate hospital but not admitted the CCU, $459(5.1 \%)$ to an advanced hospital but not the CCU, 3396 (37.5\%) to the CCU in an intermediate hospital, and 4630 $(51.2 \%)$ to the CCU in an advanced hospital. This distribution showed considerable variability, depending on the area participating in the study (Figure). A total of 1020 patients $(11.3 \% ; 95 \%$ CI, $10.6 \%-11.9 \%)$ were not admitted to a CCU. When analyzing those who arrived within the first 48 hours of onset, this percentage was $8.0 \%$.

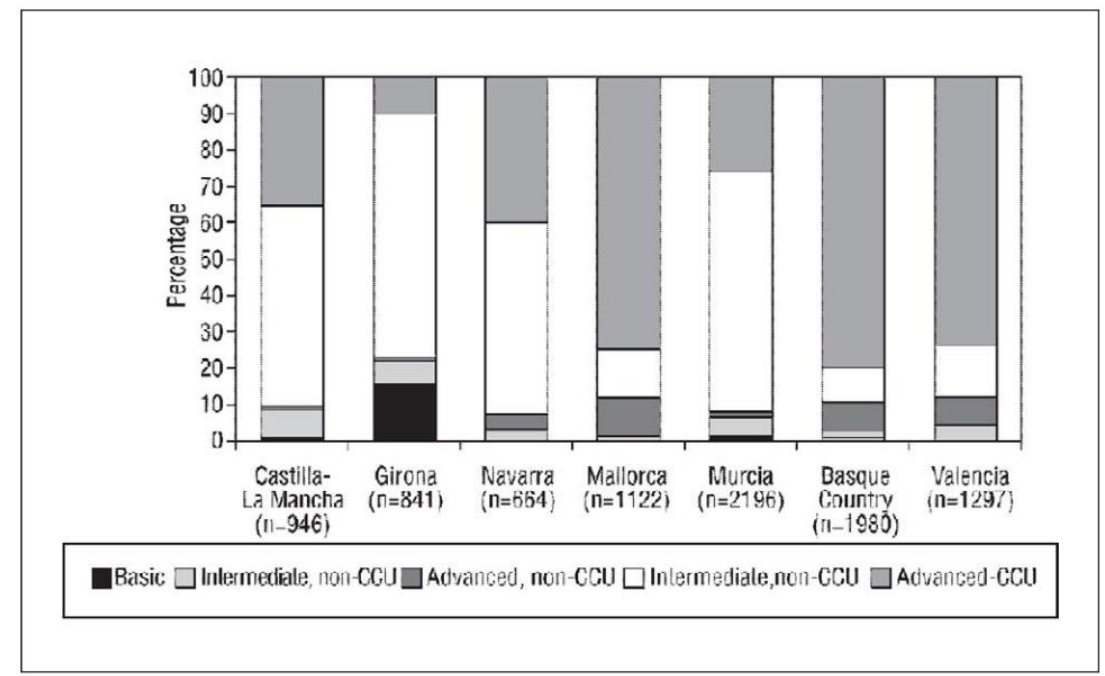

Fig. 1. Distribution of the 9046 patients of the IBERICA study by area, according to treatment hospital type and admission to a coronary care unit (CCU). Basic hospital: no CCU or catheterization laboratory; Intermediate hospital: $\mathrm{CCU}$, but no catheterization laboratory; Advanced hospital: CCU and catheterization laboratory

Table 1 indicates the patient characteristics according to treatment hospital type and admission to a CCU. The patients admitted to basic hospitals were significantly older, more often women, non-smokers and diabetics, and had a more extensive history of angina and congestive heart failure than the others. These patients received less thrombolysis, antiplatelet therapy, beta-blockers and angiotensin-converting enzyme (ACE) inhibitors than patients from the other hospitals, and were less likely to undergo coronary angiography, stress tests and echocardiography (Table 2). Patients who were admitted to an intermediate or advanced hospital but not admitted to a CCU presented intermediate characteristics between the patients in basic hospitals and those in intermediate or advanced hospitals who were admitted to a CCU, and a linear trend was observed between these defined groups (Tables 1 and 2). 
Table 1. Patient History and Characteristics of AMI Episode in Patients Participating in the IBERICA Study by the Type of Hospital and Admission in $\operatorname{CCU}(\mathrm{n}=9046)^{*}$

\begin{tabular}{|c|c|c|c|c|c|c|c|}
\hline & \multicolumn{5}{|c|}{ Type of Hospital and Admission in CCU } & \multirow[b]{2}{*}{$P$} & \multirow[b]{2}{*}{ Trend $P^{\dagger}$} \\
\hline & $\begin{array}{c}\text { Basic } \\
(n=202)\end{array}$ & $\begin{array}{c}\text { Intermediate, } \\
\text { Non-CCU } \\
(n=359)\end{array}$ & $\begin{array}{l}\text { Advanced, } \\
\text { Non-CCU } \\
(n=459)\end{array}$ & $\begin{array}{l}\text { Intermediate, } \\
\text { CCU }(n=3396)\end{array}$ & $\begin{array}{c}\text { Advanced, } \\
\text { CCU }(n=4630)\end{array}$ & & \\
\hline \multicolumn{8}{|l|}{ Cardiovascular risk factors } \\
\hline Age, mean \pm SD & $66.2 \pm 7.8$ & $63.9 \pm 9.5$ & $63.1 \pm 9.2$ & $61.5 \pm 10.0$ & $60.3 \pm 10.4$ & $<.001$ & $<.001 \ddagger$ \\
\hline Hypertension, \% & 50.8 & 55.4 & 53.9 & 45.4 & 44.4 & $<.001$ & $<.001$ \\
\hline Diabetes, $\%$ & 39.9 & 37.8 & 33.0 & 29.5 & 27.3 & $<.001$ & $<.001$ \\
\hline Smoking, \% & 24.2 & 28.7 & 36.1 & 44.0 & 47.5 & $<.001$ & $<.001$ \\
\hline \multicolumn{8}{|l|}{ Prior history } \\
\hline Previous angina, $\%$ & 50.8 & 44.8 & 44.9 & 42.7 & 40.9 & .021 & .001 \\
\hline Previous AMI, $\%$ & 24.6 & 22.8 & 27.1 & 16.4 & 16.9 & $<.001$ & $<.001$ \\
\hline Heart failure, \% & 12.6 & 13.4 & 14.7 & 5.8 & 6.0 & $<.001$ & $<.001$ \\
\hline \multicolumn{8}{|l|}{ Characteristics of the event } \\
\hline (median [P5-P95]) & $(15-2664)$ & $(15-2880)$ & $(0-2880)$ & $(20-1440)$ & $(10-1278)$ & $<.001$ & $<.001$ \\
\hline Anterior AMI & 34.9 & 38.8 & 30.5 & 35.1 & 35.2. & 221 & 938 \\
\hline Non-Q-wave AMI & 16.9 & 14.4 & 23.1 & 15.1 & 14.3 & $<.001$ & $<.001$ \\
\hline Killip at admission $\geq 3$ & 13.4 & 16.7 & 17.5 & 8.6 & 8.3 & $<.001$ & $<.001$ \\
\hline
\end{tabular}

\footnotetext{
*SD indicates standard deviation; AMI, acute myocardial infarction; CCU, coronary care unit. $\dagger P$ trend: chi-square for trends.

$\ddagger P$ trend by Spearman correlation coefficient.

$\$$ Median (5th percentile and 95th percentile).
}

Table 2. Diagnostic and Therapeutic Procedures, Complications of the AMI Episode in IBERICA Study Subjects According to Treatment Hospital Type and Admission to CCU ( $\mathrm{n}=9046)^{*}$

\begin{tabular}{|c|c|c|c|c|c|c|c|}
\hline & \multicolumn{5}{|c|}{ Type of Hospital and Admission in CCU } & \multirow[b]{2}{*}{$P$} & \multirow[b]{2}{*}{$P$ Trend $\dagger$} \\
\hline & $\begin{array}{c}\text { Basic } \\
(n=202)\end{array}$ & $\begin{array}{c}\text { Intermediate, } \\
\text { Non-CCU } \\
(n=359)\end{array}$ & $\begin{array}{l}\text { Advanced, } \\
\text { Non-CCU } \\
(n=459)\end{array}$ & $\begin{array}{l}\text { Intermediate, } \\
\text { CCU }(n=3396)\end{array}$ & $\begin{array}{c}\text { Advanced, } \\
\text { CCU } \\
(n=4630)\end{array}$ & & \\
\hline \multicolumn{8}{|l|}{ Drugs, \% } \\
\hline ASA & 77.3 & 79.5 & 76.8 & 96.6 & 96.4 & $<.001$ & $<.001$ \\
\hline Beta-blockers & 24.9 & 30.3 & 39.5 & 52.7 & 56.2 & $<.001$ & $<.001$ \\
\hline ACE inhibitors & 33.0 & 40.4 & 35.8 & 51.5 & 47.6 & $<.001$ & $<.001$ \\
\hline \multicolumn{8}{|l|}{ Procedures, $\%$} \\
\hline Coronary angiography & 4.8 & 18.3 & 23.7 & 27.9 & 39.5 & $<.001$ & $<.001$ \\
\hline Echocardiography & 26.4 & 54.8 & 66.1 & 73.0 & 82.8 & $<.001$ & $<.001$ \\
\hline Stress test & 19.9 & 30.8 & 37.1 & 51.9 & 50.3 & $<.001$ & $<.001$ \\
\hline Surgery & 0.5 & 0.9 & 0.7 & 2.3 & 4.3 & $<.001$ & $<.001$ \\
\hline \multicolumn{8}{|c|}{ Complications in acute phase, $\%$} \\
\hline Severe arrhythmias & 18.1 & 18.2 & 17.8 & 12.0 & 14.5 & $<.001$ & .187 \\
\hline Maximum Killip $\geq 3$ & 25.7 & 27.0 & 24.1 & 18.0 & 17.5 & $<.001$ & $<.001$ \\
\hline \multicolumn{8}{|l|}{ Case-fatality, $\%$} \\
\hline $0-28$ days & 38.1 & 33.7 & 29.6 & 11.5 & 11.6 & $<.001$ & $<.001$ \\
\hline $0-1 \mathrm{~h}$ & 3.5 & 4.2 & 5.4 & 0.3 & 0.5 & $<.001$ & $<.001$ \\
\hline $0-24 \mathrm{~h}$ & 22.3 & 25.9 & 22.2 & 4.4 & 4.1 & $<.001$ & $<.001$ \\
\hline $24 \mathrm{~h}-28$ days & 20.4 & 10.5 & 9.5 & 7.5 & 7.8 & $<.001$ & $<.001$ \\
\hline
\end{tabular}

* ASA indicates antiplatelet therapy; AMI, acute myocardial infarction; ACE inhibitors, angiotensin-converting enzyme inhibitors ; $\mathrm{CCU}$, coronary care unit. $\dagger \mathrm{P}$ trend: chi-square for trends 
The 28-day case-fatality was $38.1 \%$ in the basic hospitals, around $30 \%$ in the intermediate and advanced hospitals in the patients not admitted to the $\mathrm{CCU}$, and $11 \%$ in patients at intermediate and advanced hospitals who were admitted to the CCU (Table 2). The patients in the basic hospitals presented higher case-fatality within the first 24 hours and during the period of 24 hours to 28 days. Patients from the intermediate or advanced hospitals who were not admitted to a CCU had higher case-fatality with respect to those who were admitted to a $\mathrm{CCU}$, although this difference was observed primarily in the first 24 hours (Table 2).

In the subgroup of patients who arrived within the first 48 hours after onset of AMI, the variables independently associated with admission to a CCU were analyzed (Table 3). Older patients and smokers had a greater probability of being admitted to a CCU, whereas non-Q-wave infarction or infarction of indeterminate location on the electrocardiogram, Killip class 4 at admission and delay in arrival to the hospital above 6 hours were associated with a lower probability of admission to a CCU.

Table 3. Associated Variables Regardless of Admission to CCU*

\begin{tabular}{lcc}
\hline & OR $(95 \% \mathrm{CI})$ & $P$ \\
\hline Age & & \\
25-54 years & 1 & \\
55-64 years & $1.47(1.14-1.92)$ & .004 \\
65-74 years & $1.29(1.03-1.60)$ & .024 \\
Sex, female & $0.85(0.69-1.06)$ & .140 \\
Smoking & $1.33(1.08-1.64)$ & .008 \\
Hypertension & $0.84(0.70-1.01)$ & .057 \\
Location & 1 & \\
Inferior AMI & & \\
Non-Q-wave & $0.62(0.49-0.78)$ & $<.001$ \\
Anterior & $0.89(0.73-1.10)$ & .282 \\
Unclassifiable & $0.34(0.23-0.50)$ & $<.001$ \\
Killip at admission & 1 & \\
1 & $0.90(0.71-1.15)$ & .400 \\
2 & $0.76(0.54-1.07)$ & .113 \\
3 & $0.63(0.40-1.00)$ & .049 \\
4 & & \\
Symptoms-monitoring & 1 & \\
$0-2 \mathrm{~h}$ & $1.12(0.87-1.42)$ & .378 \\
2-4 h & $1.01(0.71-1.42)$ & .967 \\
$4-6 \mathrm{~h}$ & $0.66(0.50-0.87)$ & .003 \\
6-12 h & $0.71(0.50-0.99)$ & .045 \\
$12-24 \mathrm{~h}$ & $0.61(0.32-1.16)$ & .134 \\
$24-36 \mathrm{~h}$ & $0.27(0.17-0.41)$ & $<.001$ \\
$36-48 \mathrm{~h}$ & & \\
& & \\
\hline
\end{tabular}

* AMI indicates acute myocardial infarction; CI, confidence interval; OR, odds ratio; $\mathrm{CCU}$, coronary care unit. Patients admitted to the hospital within the first 48 hours and with valid information on the delay in arrival at the hospital were selected $(n=7708)$

Table 4 indicates the patient characteristics, according to vital status at 28 days. The variables that differed between patients according to the hospital type were also associated with higher 28-day casefatality. 
Table 4. Variables Associated With 28-Day Mortality After AMI in Patients in the IBERICA Study (n=9046)*

\begin{tabular}{|c|c|c|c|}
\hline \multicolumn{4}{|l|}{ Cardiovascular risk factors } \\
\hline Sex, women $(\%)$ & 18.8 & 27.9 & $<.001$ \\
\hline Hypertension, \% & 44.5 & 54.8 & $<.001$ \\
\hline Diabetes, $\%$ & 26.8 & 43.3 & $<.001$ \\
\hline \multicolumn{4}{|l|}{ Prior history, $\%$} \\
\hline Previous angina & 40.9 & 50.3 & $<.001$ \\
\hline Previous AMI & 15.5 & 31.3 & $<.001$ \\
\hline Heart failure & 4.8 & 20.0 & $<.001$ \\
\hline \multicolumn{4}{|l|}{ Characteristics of the event, $\%$} \\
\hline Anterior location on ECG & 34.1 & 41.9 & $<.001$ \\
\hline Antiplatelet therapy & 98.6 & 66.4 & $<.001$ \\
\hline Beta-blockers & 58.1 & 14.1 & $<.001$ \\
\hline ACE inhibitors & 51.3 & 25.1 & $<.001$ \\
\hline \multicolumn{4}{|l|}{ Procedures, $\%$} \\
\hline Coronary angiography & 35.8 & 13.9 & $<.001$ \\
\hline Surgery & 3.2 & 3.2 & .928 \\
\hline Coronary angioplasty & 17.4 & 6.1 & $<.001$ \\
\hline \multicolumn{4}{|l|}{ Complications in acute phase, $\%$} \\
\hline Tachycardia/ventricular fibrillation & 9.2 & 46.9 & $<.001$ \\
\hline Maximum Killip $\geq 3$ & 10.7 & 73.0 & $<.001$ \\
\hline
\end{tabular}

* SD indicates standard deviation; ECG, electrocardiogram; AMI, acute myocardial infarction; ACE inhibitors, angiotensinconverting enzyme inhibitors

When analyzing the association between the case fatality and the hospital type and CCU admission, admission to a CCU (whether in an intermediate or advanced hospital) was found to be associated with lower 28-day case-fatality (Table 5). This lower mortality remained the same, even after adjusting for AMI severity (Model 3), and for variables related to the AMI treatment (Model 4). Admission to an advanced hospital without admission to a CCU was also associated with lower 28-day case-fatality. 
Table 5. Adjusted Odds Ratio (OR) and 95\% CI for Overall 28-Day Case-Fatality, 24-h Case-Fatality and 1- to 28-Day CaseFatality Among 24-h Survivors, According to Treatment Hospital Type and Admission or Not to CCU*

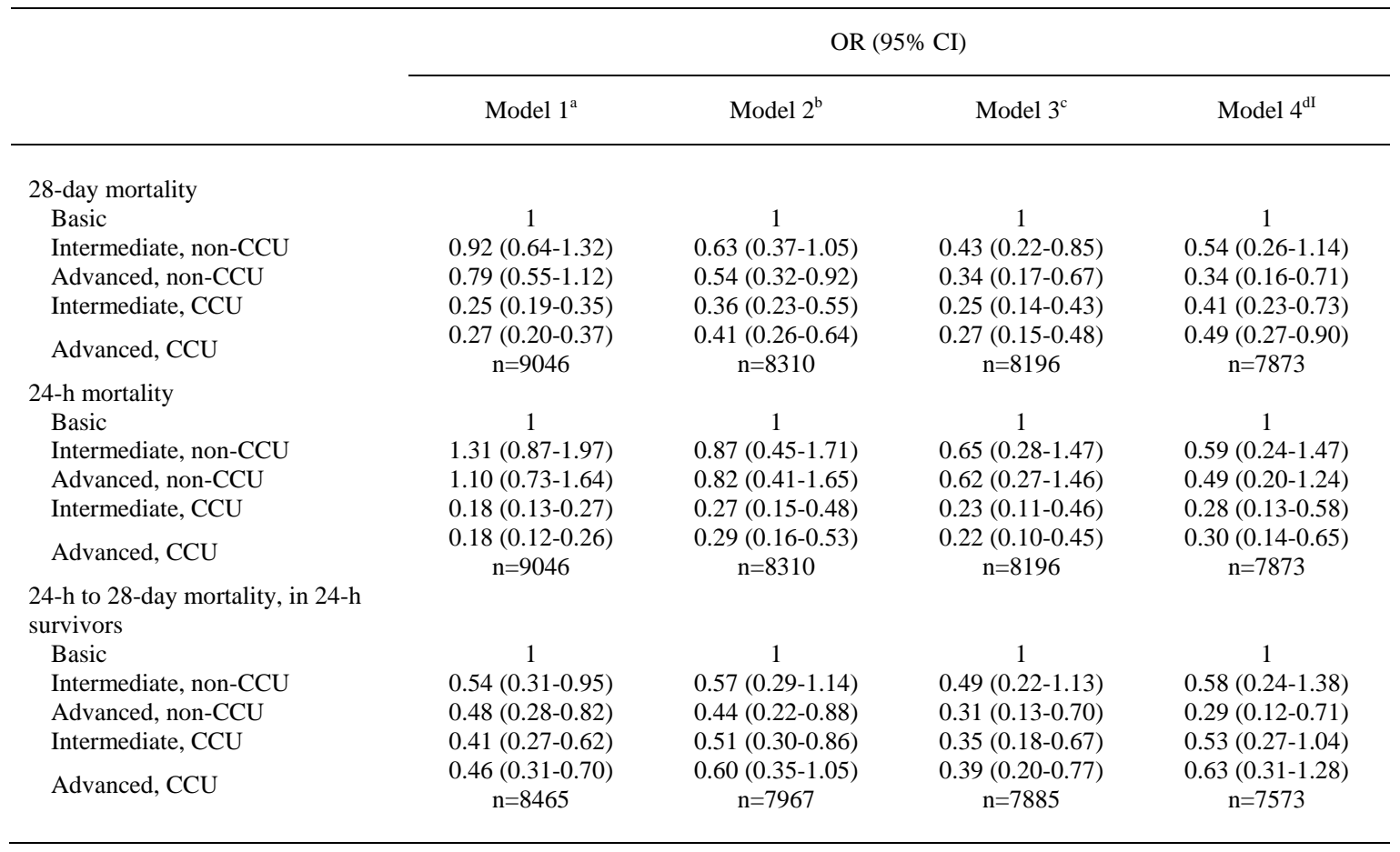

* CI indicates confidence interval; CCU, coronary care unit. ${ }^{a}$ Model 1: adjusting for age and sex. ${ }^{\mathrm{b}}$ Model 2: adjusting for age, sex, smoking, hypertension, diabetes, AMI location and prior history of AMI, angina, or heart failure. ${ }^{\mathrm{c}}$ Model 3: adjusting for the same variables as Model 2, as well as maximum Killip during admission and malignant ventricular arrhythmia as indicators of severity. ${ }^{\mathrm{d}}$ Model 4: adjusting for the same variables as Model 3, as well as thrombolysis, antiplatelet therapy, and coronary angiography as indicators of patient treatment

Furthermore, admission to a CCU was associated with lower 24-hour case-fatality. This lower casefatality remained the same, even after adjusting for AMI severity or for the treatment-related variables. These results remained unchanged when the patients who survived the first hour were selected, in both intermediate $(\mathrm{OR}=0.31 ; 95 \% \mathrm{CI}, 0.17-0.57)$ and advanced hospitals $(\mathrm{OR}=0.30 ; 95 \% \mathrm{CI}, 0.16-0.57)$.

When the analysis was limited to 24-hour survivors, it was observed that admission to an intermediate (in the CCU) or advanced hospital (regardless of admission to a CCU or not) was associated with lower 28-day case-fatality. This association persisted even after adjusting for the severity of the AMI. The type of hospital where the patient was treated no longer had a protective effect against mortality, except when the patient was admitted to an advanced hospital but not a CCU, which continued to be associated with lower case-fatality after adjusting for the variables related to AMI treatment (antiplatelet therapy, thrombolysis, and coronary angiography). After adjusting for antiplatelet therapy and thrombolysis or for angiography coronary in two different models, admission to a CCU or to an advanced hospital but not to a CCU was still associated with lower case-fatality (data not shown).

An analysis to determine whether admission to a CCU or general ICU was associated with different mortality showed no differences in 28-day case-fatality (admission to a general ICU versus a CCU, $\mathrm{OR}=0.96$; 95\% CI, 0.73-1.25). 


\section{Discussion}

In this population-based hospital registry of patients with AMI, we observed that about $11 \%$ of the patients between 25 and 74 years of age who were admitted to a hospital for AMI were not admitted to a CCU. Older patients and smokers had a greater probability of being admitted to a CCU, whereas a delay in hospital arrival, Killip class 4 at admission and non-Q-wave or infarction of indeterminate location were associated with a lower probability of admission. Non-admission to a CCU was associated with higher 28-day case-fatality, mainly at the expense of greater mortality in the first 24 hours.

This registry also showed that around $2 \%$ of the patients with AMI were admitted to a basic hospital. This admission was associated with higher 28-day case-fatality in 24-hour survivors, an outcome partially explained by differences in treatment.

\section{Admission to a CCU and Associated Variables}

Despite the recommendations of the treatment guidelines, ${ }^{2-4}$ it is interesting to note that $11.3 \%$ of the patients were not admitted to a CCU.

The evidence suggests that more seriously ill patients could benefit most from treatment in a CCU. ${ }^{18}$ Paradoxically, in our study the group of patients who were not admitted to a CCU presented a poorer baseline profile, greater frequency of high Killip class at admission and during hospitalization, and a higher incidence of malignant ventricular arrhythmia than those admitted to a CCU. In addition, Killip class 4 at admission was associated with a lower probability of admission to a CCU in the multivariate analysis. These data are consistent with the findings of a study conducted in the United States, which showed that AMI patients transferred from a community hospital to a tertiary hospital had a lower score on the severity scales and significantly lower 30-day case-fatality than patients who were not transferred. ${ }^{19}$

In this context, the use of risk stratification algorithms for patients with AMI based on easy-tomeasure clinical characteristics at the time of admission are recommended to establish the best therapeutic approach. ${ }^{18}$ The Integrated Ischemic Heart Disease Plan in Spain underscores the fact that a broad difference in the use of effective diagnostic and therapeutic procedures is not acceptable, because of the potential impact on patient mortality and morbidity. ${ }^{20}$

Another interesting point is that most patients seen in basic hospitals were found in Girona. This is probably the result of the health structure used in Catalonia, in which an emphasis has been placed on hospital proximity to the non-urban population over hospital specialization. Nevertheless, the total sum of patients seen in the basic hospitals and those not admitted to a CCU does show considerable variability between areas, suggesting that CCU accessibility is similar in the areas studied.

\section{Type of Hospital, Admission to a CCU and Case-Fatality}

The higher case-fatality observed in patients not admitted to a CCU could be related to 3 factors: differences in the characteristics of patients admitted to the various hospital types defined, differences in AMI treatment in these hospitals, or differences in the accessibility of secondary and tertiary resources.

The greater comorbidity and severity of patients not admitted to a CCU could explain the greater mortality. ${ }^{21,22}$ Nevertheless, in our study these variables did not explain the entire difference in 28-day and 24-hour case-fatality observed. Furthermore, differences in treatment did not explain the higher 24hour case-fatality of patients not admitted to a CCU, although it did explain the lower 24-h to 28-day case-fatality in the case of patients admitted to a CCU. These observations reaffirm the importance of CCUs in treatment during the early hours of AMI. Although the results were the same when selecting the survivors at one hour after the onset of symptoms, we cannot rule out the possibility that these patients died due to AMI severity within the first few hours and therefore could not be admitted to a CCU.

Another important observation is that patients treated in a basic hospital presented a higher 24-h to 28day case-fatality rate, regardless of the comorbidity and severity of the AMI. The lower use of thrombolysis, antiplatelet therapy and coronary angiography partially explained this higher case-fatality. In our study, the overall use of thrombolysis (43\%) was less than that observed in series of patients admitted to the $\mathrm{CCU},{ }^{23}$ particularly in basic hospitals $(6.4 \%)$. The same conclusions are obtained when analyzing the use of antiplatelet therapy, beta-blockers, and ACE inhibitors. This variability in treatment between hospitals has already been reported in patients admitted to the CCU, ${ }^{14,15}$ but is even greater when patients not admitted to the CCU are included. ${ }^{16}$ These results support the need to disseminate and use clinical practice guidelines for the treatment of AMI 2 based on the best scientific evidence available, in order to decrease mortality. 
Differences in the accessibility of tertiary resources could also explain this higher case-fatality. In our study, more coronary angiographies and angioplasties were performed in the advanced hospitals than the intermediate and basic hospitals, lending support to the hypothesis suggested by previous studies ${ }^{5,6,8}$ that the number of diagnostic and therapeutic procedures the patient receives is determined mainly by the resources available at the admitting hospital. Nevertheless, we did not observe significant differences in 28-day case-fatality when comparing intermediate and advanced hospitals. In addition, when adjusting the analyses for the use of coronary angiography without including the medical therapies (antiplatelet therapy and thrombolysis), the association between admission to a CCU or an advanced hospital continued to be associated with a lower case-fatality. These data are consistent with the results of other observational studies indicating that the variability in the use of tertiary procedures does not appear to determine differences in the short- to medium-term case-fatality between intermediate and advanced hospitals if the patients with an indication for urgent coronary angiography at the intermediate centers are referred to advanced centers. $5,8-10$

The lower case-fatality observed in these hospitals is probably related to multiple factors, such as improved treatment and greater accessibility of secondary and tertiary resources.

A recent publication based on the minimum basic data set showed that the raw and adjusted inhospital case-fatality for ischemic heart disease and heart failure in the best general and teaching hospitals in Spain was above the case-fatality observed in the best county hospitals. ${ }^{24}$ The difference with our results, which showed a higher raw case-fatality in basic hospitals, probably can be attributed to the fact that the former did not include patients who died in the emergency room prior to admission to the hospital and included patients with heart failure as well as forms of ischemic heart disease other than AMI.

\section{Characteristics and Limitations of the Study}

This analysis was based on a population-based hospital registry in various regions of Spain that allowed patients not admitted to a $\mathrm{CCU}$ or remaining in basic hospitals to be characterized and comparatively analyzed with regard to clinical progress. These patients rarely participate in epidemiological or clinical studies on AMI treatment.

The data of patients not admitted to a CCU were compiled retrospectively from the clinical history, and it was impossible to analyze the clinical evidence used to limit access to the CCU (terminal status or extremely limited quality of life, for instance).

\section{Conclusions}

One out of every ten patients between 25 and 74 years of age who presented an AMI and arrived at a hospital alive were not admitted to a CCU. Many of these patients, particularly the most severe cases (Killip 4 at admission), could benefit from CCU admission. CCU admission was associated with lower 28-day case-fatality, particularly within the first 24 hours, regardless of whether the hospital where the patient was admitted had a catheterization laboratory.

Admission to a CCU, or to a hospital with a catheterization laboratory but not to a CCU, was associated with lower 24-h to 28-day case-fatality, with respect to admission in a basic hospital. Differences in thrombolysis, antiplatelet therapy, and coronary angiography partially explain this observation.

\section{Acknowledgements}

The authors gratefully acknowledge the fieldwork done by L. Villar, D. Constela, A. García, P. Piñera, C. Llamas, A.M. Calvo, A. Aragón, and R. Marco, as well as valuable comments made by J.A. Melgarejo. 


\section{References}

1. J Marrugat, R Elosua, H Martí. Epidemiología de la cardiopatía isquémica en España: estimación del número de casos y de las tendencias entre 1997 y 2005. Rev Esp Cardiol, 55 (2002), pp. 337-346.

2. F Arós, A Loma-Osorio, A Alonso, JJ Alonso, A Cabadés, I Coma-Canella, et al. Guías de actuación clínica de la Sociedad Española de Cardiología en el infarto agudo de miocardio. Rev Esp Cardiol, 52 (1999), pp. 919-995.

3. TJ Ryan, EM Antman, NH Brooks, RM Califf, LD Hillis, LF Hiratzka, et al. 1999 Update: ACC/AHA guidelines for the management of patients with acute myocardial infarction. A report of the American College of Cardiology/American Heart Association Task Force on Practice Guidelines. J Am Coll Cardiol, 34 (1999), pp. 890-911.

4. DG Julian, JP Boissel, DP De Bono, K Fox, M Genoni, J Heikkila, et al. Acute myocardial infarction: pre-hospital and in-hospital management. Task Force of the European Society of Cardiology. Eur Heart J, 17 (1996), pp. 43 63.

5. J Marrugat, G Sanz, R Masia, V Valle, L Molina, M Cardona, et al. Six-month outcome in patients with myocardial infarction initially admitted to tertiary and nontertiary hospitals. RESCATE Investigators. J Am Coll Cardiol, 30 (1997), pp. 1187-1192.

6. J Marrugat, J Ferrieres, R Masia, J Ruidavets, J Sala. Differences in use of coronary angiography and outcome of myocardial infarction in Toulouse (France) and Gerona (Spain). The MONICA-Toulouse and REGICOR investigators. Eur Heart J, 21 (2000), pp. 740-746.

7. F Arós, J Marrugat, L López-Bescós, A Cabadés, A Loma-Osorio, X Bosch, PRIAMHO Investigators. Accessibility to coronary angiography and one-year survival after myocardial infarction. Am J Cardiol, 90 (2002), pp. 409-412.

8. NR Every, EB Larson, PE Litwin, C Maynard, SD Fihn, MS Eisen-berg, et al. The association between on-site cardiac catheterization facilities and the use of coronary angiography after acute myocardial infarction. Myocardial Infarction Triage and Intervention Project Investigators. N Engl J Med, 329 (1993), pp. 546-551.

9. JV Selby, BH Fireman, RJ Lundstrom, BE Swain, AF Truman, CC Wong, et al. Variation among hospitals in coronary-angiography practices and outcomes after myocardial infarction in a large health maintenance organization. N Engl J Med, 335 (1996), pp. 1888-1896.

10. JL Rouleau, LA Moye, MA Pfeffer, JM Arnold, V Bernstein, TE Cuddy, et al. A comparison of management patterns after acute myocardial infarction in Canada and the United States. The SAVE investigators. N Engl J Med, 328 (1993), pp. 779-784.

11. DB Mark, CD Naylor, MA Hlatky, RM Califf, EJ Topol, CB Granger, et al. Use of medical resources and quality of life after acute myocardial infarction in Canada and the United States. N Engl J Med, 331 (1994), pp. 11301135 .

12. Ley 14/1986. Boletín Oficial del Estado. BOE 29-4-1986, núm. 102.

13. Ley 16/2003. Boletín Oficial del Estado. BOE 29-5-2003, núm. 128.

14. A Cabadés, L López-Bescós, F Arós, A Loma-Osorio, X Bosch, P Pabón, et al. Variabilidad en el manejo y pronóstico a corto y medio plazo del infarto de miocardio en España: el estudio PRIAMHO. Rev Esp Cardiol, 52 (1999), pp. 767-775.

15. F Arós, J Cuñat, A Loma-Osorio, E Torrado, X Bosch, JJ Rodríguez, et al. Tratamiento del infarto agudo de miocardio en España en el año 2000. H estudio PRIAMHO II. Rev Esp Cardiol, 56 (2003), pp. 1165-1173

16. M Fiol, A Cabadés, J Sala, J Marrugat, R Elosua, G Vega, et al. Variabilidad en el manejo hospitalario del infarto agudo de miocardio en España. Estudio IBERICA. Rev Esp Cardiol, 54 (2001), pp. 443-452.

17. H Tunstall-Pedoe, K Kuulasmaa, P Amouyel, D Arveiler, AM Rajakangas, A Pajak. WHO MONICA Project. Myocardial Infarction and coronary deaths in the World Health Organization MONICA Project. Registration procedures, event rates, and case fatality rates in 38 populations from 21 countries in four continents. Circulation, 90 (1994), pp. 583-612.

18. W Weintraub. Prediction scores after myocardial infarction: Value, limitations and future directions. Circulation, 106 (2002), pp. 2292-2293.

19. RH Mehta, EJ Stalhandske, PA McCargar, TJ Ruane, KA Eagle. Elderly patients at highest risk with acute myocardial infarction are more frequently transferred from community hospitals to tertiary centers: reality or myth?. Am Heart J, 138 (1999), pp. 688-695.

20. Plan Integral de Cardiopatía Isquémica 2004-2007 [updated 27/01/2004]. Ministerio de Sanidad y Consumo. Available from: http://www.msc.es/planesIntegrales/PICI/pdf/cardiopatia.pdf (2003).

21. J Marrugat, J Sala, R Masia, M Pavesi, G Sanz, V Valle, for the RESCATE Investigators, et al. Mortality differences between men and women with first myocardial infarction. JAMA, 280 (1998), pp. 1405-1409.

22. I Rohlfs, R Elosua, R Masia, J Sala, J Marrugat. Tendencias en la proporción de pacientes menores de 75 años con infarto agudo de miocardio que presentan Killip III-IV. Variables asociadas con su aparición y con el pronóstico: 1978-1997. Rev Esp Cardiol, 5 (2002), pp. 1117-1123.

23. X Bosch, A Sambola, F Arós, L López-Bescós, X Mancisidor, J Illa. Utilización de la trombólisis en los pacientes con infarto agudo de miocardio en España: observaciones del estudio PRIAMHO. Rev Esp Cardiol, 53 (2000), pp. 490-501. 